\title{
TEMPORALIDADES ALTERADAS: ACONTECIMIENTO, INTERRUPCIÓN Y MULTIPLICIDAD. REFLEXIONES A RAÍZ DE LA PANDEMIA
}

\author{
ALTERED TEMPORALITIES: EVENT, INTERRUPTION \\ AND MULTIPLICITY. REFLECTIONS \\ ON THE PANDEMIC
}

\author{
Aránzazu Hernández Piñero \\ Universidad de Zaragoza \\ aranzazu@unizar.es
}

La realidad tiene la desconcertante costumbre de enfrentarnos a lo inesperado, para lo que no estamos preparados.

Hannah Arendt ${ }^{1}$

... a condición de liberarnos de nuestros propios déspotas interiores, somos los seres más poéticos [...] del mundo.

Hélène Cixous ${ }^{2}$

Mis reflexiones sobre los significados de la pandemia parten del siguiente planteamiento, que, por razones de extensión, solo enunciaré: (1) la pandemia del covid-19 es un fenómeno posthumano y (2) vivimos múltiples tiempos. La pandemia es un fenómeno posthumano debido a que en él se interrelacionan animales no humanos y humanos, naturaleza, tecnología y capitalismo global; fenómeno que tiene su origen en una visión androcéntrica, patriarcal, mecanicista, capitalista, colonial y militarista del mundo. A su vez, vivimos múltiples tiempos ${ }^{3}$ : habitamos una pluralidad de tiempos que se yuxtaponen y/o simultanean, generando paradojas y

1 Arendt, H. «La mentira en política: reflexiones sobre los documentos del Pentágono», en H. Arentd, Crisis de la República, Madrid, Taurus, 1998, p. 14.

2 Cixous, H. y Calle-Gruber, M. Fotos de raices. Memoria y escritura, México, Taurus, 2001, p. 131.

${ }^{3}$ Me inspiro en la noción de «multiplicidad de los tiempos» de María Zambrano: v. ZAMBrano, M. Delirio y destino. Los veinte años de una española, Madrid, horas y HORAS, 2011, pp. 129-139.

DOI: https://doi.org/10.25145/j.laguna.2021.49.06

Revista Laguna, 49; diciembre 2021, pp. 95-102; ISSN: e-2530-8351 
conflictos con la comprensión lineal del tiempo propia de la modernidad eurooccidental, patriarcal y colonial así como de la de la posmodernidad neoliberal ${ }^{4}$.

Las teorías feministas, antirracistas y poscoloniales no solo han discutido ampliamente la concepción lineal del tiempo sino que han propuesto modos alternativos de pensar la temporalidad como, por ejemplo, las reflexiones de Luce Irigaray acerca del tiempo a la luz de la diferencia sexual, la idea del doble nivel del tiempo (lineal y cíclico) de Julia Kristeva, la «heterogenidad multi-temporal» de lo ch'ixi y el qhipnayra de Silvia Rivera Cusicanqui, las temporalidades multidimensionales de Stuart Hall o la temporalidad nómada de Rosi Bradotti, por citar solo algunos de los planteamientos que conozco mejor ${ }^{5}$. En suma, el tiempo del capitalismo, tanto moderno-colonial como posmoderno-colonial, no es el único tiempo que existe, aunque tenga esa pretensión.

Con estas consideraciones en mente, me pregunté por los efectos de la pandemia en nuestra vivencia de la temporalidad y por su cualidad temporal. También me interrogué acerca de cómo la temporalidad o temporalidades de la pandemia afecta(n) a y se ve(n) afectada(s) por la temporalidad neoliberal. En relación con lo anterior, me planteé si, quizás, estas experiencias temporales nos ofrecen pistas sobre cómo estar presentes en el presente, indicios que nos permitan salir del presente saturado al que se refiere Braidotti ${ }^{6}$. Fue la rapidez con la que los medios de comunicación empezaron a hablar del "después» lo que me llevó a pensar en esta última cuestión. Por ejemplo, el suplemento ideas de El País dedicaba su número del 3 de mayo de 2020 a «El futuro después del coronavirus», con un encabezamiento que rezaba así: «¿Cómo será el mundo que nos espera a la salida de esta crisis? ¿Qué rumbo debemos tomar? 60 expertos y pensadores nos ofrecen su visión de las claves de la nueva era». Esta premura por el «después», por el «futuro» me pareció una

4 Tomo, grosso modo, el análisis elaborado por Rosi Braidotti de la condición posthumana. Sigo también su caracterización de las diferencias entre la concepción de la temporalidad de la modernidad y la de la posmodernidad: mientras que el tiempo en la modernidad es pensado en términos de linealidad y teleología, en la posmodernidad es desprovisto de estas característica y concebido como presente. V. Metamorfosis. Hacia una teoría materialista del devenir, Madrid, Akal, 2005; Transposiciones. Sobre la ética nómada, Barcelona, Gedisa, 2009; Lo Posthumano, Barcelona, Gedisa, 2015 y Por una politica afirmativa. Itinerarios éticos, Barcelona, Gedisa, 2018.

5 Para las obras de Braidotti remito a la nota anterior. Para los otros trabajos referidos: v. Hall, S. [1992], «¿Cuándo fue lo poscolonial? Pensar al límite», en S. Mezzadra (comp.), Estudios postcoloniales. Ensayos fundamentales, Madrid, Traficantes de sueños, 2008, pp. 121-144; Irigaray, L. [1984], Etica de la diferencia sexual, Pontevedra, Ellago Ediciones, 2010; Kristeva, J. "Le temps des femmes", Cahiers de recherche de sciencies des textes et documents, 5, 1979, pp. 5-19 y RIVERA CusiCANQUI, S. Un mundo ch'ixi es posible. Ensayos desde un presente en crisis, Buenos Aires, Tinta Limón, 2018.

${ }^{6}$ V. Braidotti, R. Transposiciones, op. cit., p. 211.

7 V. VV. AA., "El futuro después del coronavirus», Suplemento ideas, n. ${ }^{\circ} 259$, El País, domingo 3 de mayo de 2020. Cabe destacar el presupuesto que anima el número del mencionado suplemento: el de que la «salida de esta crisis» vendrá de mano de «expertos». Para una aguda crítica al papel de los expertos (empleo el género masculino intencionadamente) en la política y el pensamiento: v. la obra citada en la nota 1 . 
suerte de huida hacia delante, una importante señal de la dificultad de estar en el presente, de sentir y vivir el presente.

\section{INTERRUPCIÓN Y ALTERACIÓN: LA PANDEMIA COMO ACONTECIMIENTO}

Me inclino a pensar que vivimos una de esas situaciones que Hélène Cixous denomina acontecimiento. Andábamos tranquilamente, o intranquilamente, con nuestras vidas y de pronto sucede algo que trastorna nuestra cotidianidad: el imprevisible. En Fotos de raices, Cixous sostiene que «nos suceden millones de cosas todos los días: somos nosotros quienes no las recibimos» porque, «enseguida, nos precipitamos hacia los clichés» ${ }^{8}$ ¿ ¿Qué podemos hacer para no precipitarnos hacia los clichés?

Cixous habla del acontecimiento como de aquello que interrumpe «el curso de la vida», a veces, la ha llamado «entredós». La escritora lo describe como sigue:

Todo aquello que hace que el curso de la vida sea interrumpido. En ese momento nos encontramos en una situación para la que no estamos absolutamente preparados. Los seres humanos están preparados para lo cotidiano, con sus ritos, con su clausura, sus comodidades, su mobiliario. Cuando llega un acontecimiento que nos expulsa de nosotros mismos, no sabemos «vivir». Pero hace falta. Nos vemos lanzados en un espacio-tiempo en el que todas las coordenadas son otras que aquellas a las que estamos acostumbrados desde siempre. Además, estas situaciones violentas siempre son nuevas?.

Un duelo, una enfermedad grave, una guerra provocan entredós, pero también, como indica la autora, ocurren "en situaciones menos agudas» ${ }^{10}$. Me parece que la pandemia del covid-19 es un acontecimiento en estos precisos sentidos descritos por Cixous. Como acontecimiento, el covid-19 nos revela la incertidumbre que nos constituye en todo momento de nuestras vidas, pero que conjuramos o intentamos conjurar en nuestra cotidianidad.

Asimismo, Cixous describe el acontecimiento en términos de interrupción: "[t]odo aquello que hace que el curso de la vida sea interrumpido" ${ }^{11}$. Tal interrupción es fruto de "un vuelco, un giro» ${ }^{12}$ : "Ha habido un giro de la suerte. No veías nada. De golpe, como revelado por un giro, ves. El giro es difícil de creer. Pero todos los giros tienen en común la ligereza de la ocasión $»^{13}$. En un artículo que circuló en internet a principios de abril pasado con el título "Lo imposible sucedió»,

${ }^{8}$ Cixous, H. y Calle-Gruber, M. op. cit., pp. 131 y 132, respectivamente.

9 Ibidem, pp. 40-41.

10 Ibidem, pp. 46-47.

${ }^{11}$ Ibidem, p. 40.

${ }^{12}$ Cixous, H. «Pequeño imprevisible», en M. Segarra (ed.), Ver con Hélène Cixous, Barcelona, Icaria, 2006, p. 18. V. también p. 30: «De repente todo da un vuelco en sentido contrario».

13 Ibidem, pp. 18-19. 
la escritora y periodista estadounidense Rebecca Solnit nos recordaba la etimología de catástrofe: «viene de una raíz que significa un vuelco repentino». Y continúa: «[h]emos llegado a una encrucijada, hemos emergido de lo que asumíamos que era la normalidad, las cosas se han dado vuelta de repente» ${ }^{14}$. Justamente lo que Cixous llama acontencimiento.

El acontecimiento como interrupción trastorna la temporalidad. Este tiempo interrumpido es también un tiempo detenido ${ }^{15}$, en la doble acepción del término: interrumpir o parar una acción o movimiento, así como pararse a considerar algo. En el sentido de la primera acepción, un tiempo parado en el que, como ha subrayado Rebecca Solnit, las «[c] osas que se suponía que eran imparables se detuvieron»" Con respecto al segundo significado, un tiempo en el que es posible detenerse a considerar algo o a alguien, demorarse, por ejemplo, "demorarse en el mirar», como propone Ângela Lorena Fuster en otro contexto ${ }^{17}$. Esta acepción nos invita a pensar en la atención: ‘a qué prestamos atención y cómo? La atención, por ejemplo, de cuando estamos distraídas ${ }^{18}$.

Jugando con la etimología de la palabra alteración, podríamos decir que la temporalidad del acontecimiento es una temporalidad alterada ( $\mathrm{De}$ pronto el tiempo se rompe ${ }^{19} \mathrm{y}$ "Ayer se ha vuelto vertiginosamente alejado $\left.{ }^{20}\right)$ : alter provoca «el giro» e introduce «en nuestra experiencia la sensación de alteración, de otro, de otra especie que somos ${ }^{21}$. Ahora pienso en este otro, esto otro que incorpora (en el sentido etimológico) lo otro en nosotros y nosotras, alterándonos: es un otro bien chiquitito, microscópico que quienes se dedican a la ciencia nos han enseñado a llamar virus, coronavirus. Helo aquí: el «derrame ínfimo», «terriblemente pequeño, de un elemento imponderable» ${ }^{22}$. Un aleteo, tal vez, de murciélago, un estornudo humano, un roce de manos, unas gotitas de saliva que flotan en el aire... $\mathrm{y}$ «[t]odo

14 Solnit, R. «Lo imposible sucedió: lo que el coronavirus puede enseńarnos sobre la esperanza", The Guardian, abril 2020. Recuperado de https://www.climaterra.org/post/lo-imposible-sucedió-lo-que-el-coronavirus-puede-enseñarnos-sobre-la-esperanza. Última consulta: 21 de abril de 2020.

${ }^{15}$ Las pensadoras italianas de la diferencia sexual emplearon la palabra «suspendido»: a modo de ejemplo, v. Minguzzi, L. "Un tempo sospeso per osservare, pensare, compredere e agire», Via Dogana 3, 14 de abril de 2020, recuperado de https://www.libreriadelledonne.it/category/puntodivista/vd3/page/10/. Última consulta: 8 de octubre de 2021.

16 Solnit, R. op. cit.

17 Fuster Peiró, A.L. «Demorarse en el mirar. La imaginación en Simone Weil, Iris Murdoch y Hannah Arendt», Daimon. Revista Internacional de Filosofia, 60, diciembre de 2013, pp. 141-58. Recuperado de https://revistas.um.es/daimon/article/view/186931. Última consulta: 10 de marzo de 2021.

${ }^{18}$ Cixous, V.H. «Conversación con el asno. Escribir ciego», en H. Cixous, El amor del lobo y otros remordimientos, Madrid, Arena Libros, 2009, p. 55. Al inicio de esta página, leemos: «No puedo escribir sin distraer la mirada de la captación. Escribo por distracción. Distraída».

19 Cixous, H. «Die Ursache-La Cosa», en H. Cixous, El amor del lobo..., op. cit., p. 80.

${ }^{20}$ Ibidem., p. 81.

${ }^{21}$ Ibidem, pp. 84-85.

22 Cixous, H. «Pequeño imprevisible», op. cit., p. 19. 
salta como una mina, incluido los tiempos $\aleph^{23}$. Esta temporalidad alterada, generada por el acontecimiento, actúa psicosomáticamente:

De repente todo da un vuelco en sentido contrario. El imprevisto mismo. Y como ocurre con todos los imprevistos famosos, que han cambiado el espíritu del mundo en estos últimos años, por ejemplo el 11 de septiembre o el incendio del castillo de Versalles, al principio no te lo crees y sin embargo los hechos están ahí: del castillo nuestro, de las torres nuestras, no quedan más que cenizas. La creencia se retrasa con respecto al hecho. Una sensación de pesadilla se introduce en la realidad y dilata su carne temporal. Nos duele la cabeza. ¿Quién lo habría creído?24.

Dilatar la «carne temporal» de la realidad. ¡Qué imagen!

En su lenguaje, más bien poco poético, diferentes asociaciones profesionales médicas han apuntado a tales vivencias (sensación de irrealidad, dolor de cabeza, problemas de concentración, insomnio). Son los síntomas, los signos somáticos, del confinamiento y de la «nueva normalidad $»^{25}$.

\section{CAMBIAR EL IMAGINARIO DEL CAMBIO}

Entrevistado en abril pasado a propósito de la pandemia del coronavirus, el filósofo camerunés Achille Mbembe afirmaba: «[e]s difícil dar un nombre a lo que está sucediendo en el mundo ${ }^{26}$. Pienso que la dificultad para encontrar palabras para nombrar lo que está sucediendo parece indicarnos la novedad de la situación que vivimos, cualidad con la que tanto Hélène Cixous como Hannah Arendt califican el acontecimiento. Esta dificultad apunta, a mi modo de ver, a «las dificultades de la comprensión», por emplear la expresión de, o a la inapropiabilidad del acontecimento a la que se refiere Cixous (que la conduce a reconocer y a aceptar el saber que se halla en el no saber: «a sentirme asombrada, a adivinar que no sé, que no sabía que podría haber sabido, que en el futuro podré seguir sin saber $»^{27}$ ).

23 Cixous, H. "Die Ursache-La Cosa», op. cit., p. 82.

24 Cixous, H. «Pequeño imprevisible», op. cit., p. 30.

25 A modo de ejemplo: v. Nadal, M.V. «Coronavirus. Más estrés y ansiedad tras el confinamiento: lo que hemos aprendido de cuarentenas pasadas», El País, 5 de abril de 2020, recuperado de https://retina.elpais.com/retina/2020/04/03/talento/1585929680_702574.html; Alonso VAQUERIZO, E. «Siete síntomas físicos de que un mes de confinamiento está afectando a la salud», El País, 15 de abril de 2020, recuperado de https://elpais.com/elpais/2020/04/15/buenavida/1586929845_593622. html; y González Harbour, B. «Reinventar la psicología: la tercera ola será mental», El País, 15 de noviembre de 2020, recuperado de https://elpais.com/sociedad/2020-11-15/reinventar-la-psicologia-la-tercera-ola-sera-mental.html. Últimas consultas: 8 de octubre de 2021.

26 Mbembe, A. «La pandemia democratiza el poder de matar. Entrevista por Diogo Bercino", artículo original publicado en Gauchazh el 31 de marzo de 2020. Recuperado de https://lavoragine.net/la-pandemia-democratiza-poder-de-matar/. Última consulta: 22 de abril de $\overline{2020 .}$

27 Cixous, H. «Pequeño imprevisible», op. cit., p. 38. 
¿Cómo evitar, parafraseando a Arendt, sumergir «en un revoltijo de familiaridades y plausibilidades todo lo que no es familiar y necesita ser comprendido ${ }^{28}$ ? La pensadora describe el movimiento de la comprensión como sigue:

Por expresarlo de manera esquemática [...], siempre que nos confrontamos con alguna novedad temible, nuestro primer impulso es a reconocerla en una reacción ciega y descontrolada, la cual es lo suficientemente fuerte como para acuñar una nueva palabra; nuestro segundo impulso parece ser recuperar el control negando que viéramos nada nuevo en absoluto y pretendiendo que ya tenemos conocimiento de algo similar; sólo un tercer impulso puede devolvernos a lo que vimos y supimos en un comienzo. Es aquí donde empieza el esfuerzo hacia una verdadera comprensión ${ }^{29}$.

El «segundo impulso» señalado por Arendt nos conduciría a la apropiación, a la reducción de lo nuevo a lo ya conocido. Como observa la pensadora, el impulso de restablecer el orden (de sentido, de significado, de experiencia, etc.) es fuerte. Y así fue: hace apenas dos semanas leíamos en los titulares de los períodicos «La pandemia se pudo haber evitado" o en los portales virtuales de noticias "Un panel de expertos señala que "la catástrofe de la pandemia podría haberse evitado" ${ }^{30}$. Me parece que, ante el acontecimiento, presas del segundo impulso arendtiano, tratamos de «recuperar el control». Somos artífices, y al mismo tiempo víctimas, de «una ultrainterpretación apresurada $»^{31}$.

¿Será esta la razón por la que, en estos momentos, nos hallamos inmersas en una vorágine de metáforas bélicas para hablar de esta pandemia? ¿Será el deseo de control, junto a una cierta falta de imaginación, lo que nos devuelve una y otra vez al imaginario bélico? Así lo sugiere Achille Mbembe cuando atribuye la dificultad de nombrar lo que está ocurriendo a la incertidumbre o, más bien, precisaría yo, a un tipo de respuesta ante la incertidumbre ${ }^{32}$. Resulta significativo, como

${ }^{28}$ Arendt, H. «XXXI. Comprensión y política. (Las dificultades de la comprensión)», en H. Arendt, Ensayos de comprensión 1930-1954. Escritos no reunidos e inéditos de Hannah Arendt, Madrid, Caparrós, Editores, 2005, p. 379.

${ }^{29}$ Ibidem, nota 11.

30 La Vanguardia, 13 de mayo 2021, recuperado de https://www.lavanguardia.com/ vida/20210513/7450366/pandemia-pudo-haber-evitado-como-parar-proxima.html. y Euronews, 12 de mayo de 2021, recuperado de https://es.euronews.com/2021/05/12/un-panel-de-expertos-senala-que-la-catastrofe-de-la-pandemia-podria-haberse-evitado. Última consulta: 15 de mayo de 2021. Recordemos la formulación paradójica de Cixous: «[m]ás tarde, tras una investigación, se demostrará que todo era previsible habría bastado con poder leer lo ilegible para haber visto lo invisible». Cixous, H. «Pequeño imprevisible», op. cit., p. 30.

${ }^{31}$ Cixous, H. «Pequeño imprevisible», op. cit., p. 23.

32 En palabras del autor: «No es solo un virus. No saber lo que está por venir es lo que hace que los estados de todo el mundo reanuden las viejas terminologías utilizadas en las guerras». Achille, A. op. cit. 
ha señalado, entre otras, la filósofa italiana Delfina Lusiardi, que se haya producido una sustitución del lenguaje de la curación y del cuidado por el lenguaje bélico ${ }^{33}$.

Es fundamental no quedar presas en este imaginario bélico-médico-científico. Considero importante criticar estos imaginarios, que reaparecen una y otra vez, pero creo que la crítica por sí sola no es fructífera: es preciso ofrecer otros imaginarios, incluidos otros imaginarios del cambio. Cambiar los imaginarios del cambio heredados de la tradición filosófica occidental. Como decía al inicio de mi intervención, estos otros imaginarios no son (solo) futuribles, ya existen: son memoria y presente. Tomémoslos en cuenta.

Para finalizar, quiero llamar nuestra atención sobre una imagen del cambio que aparece en algunas de la autoras con quienes he pensado: la de metamorfosis. Esta aparece con frecuencia en la obra de Braidotti, quien, por ejemplo, titula su libro de 2002 Metamorfosis. Hacia una teoría materialista del devenir. En la escritura de Rebecca Solnit, quien, cuando reflexiona acerca de la pandemia, establece una analogía entre el momento presente y la oruga que entra en la crisálida ${ }^{34}$. La encontramos asimismo en las pensadoras italianas de la diferencia sexual, que nutren mi manera de entender y practicar el pensamiento y la política. En un artículo publicado en 2013, la filósofa italiana Anna Maria Piussi nos invita a «mirar con confianza» a los «elementos de promesa y de apertura en el presente»:

Con la confianza que viene del repensar nuestro imaginario sobre el cambio social [...]: no como un cambio revolucionario y excepcional, a la manera masculina, sino como metamorfosis, una transformación desde el interior extendida y radical como puede ser el paso de oruga a mariposa. Las metamorfosis no son lineales y requieren tiempos largos, pero se nutren de pasos o pasajes del ser repentinos, y de conflictos [fecundos $]^{35}$.

Para pensar en otras claves, para actuar otros imaginarios, el trabajo con las imágenes, las metáforas y las palabras me parece clave. La palabra tiene, siguiendo a Arendt, una "cualidad de apertura ${ }^{36}$. Son las palabras que pierden su cualidad de

33 Desarrollar este análisis excede los límites del presente texto. Para una aproximación al planteamiento de la filósofa italiana: v. LUSIARDI, D. «Da cuore a cuore. Invenzioni per sopravvivere all'eclissi del corpo", Grande Seminario de Diotima "Contagi e contaminazioni. La politica delle donne a confronto con il reale», Secondo incontro del 16 ottobre 2020, http://www.diotimafilosofe.it/senza-categoria/video-del-grande-seminario-di-diotima-2020/. Última consulta 25 de mayo de 2021.

34 Solnit, R. op. cit., p. 6. En una obra dos décadas anterior a la citada, publicada originalmente en 2004 y ampliada en 2016, Solnit ya había expresado la necesidad de cambiar los imaginarios del cambio: v. Solnit, R. Esperanza en la oscuridad. La historia jamás contada del poder de la gente, Madrid, Capitán Swing, 2018.

35 Piussi, A.M. "Volver a empezar. Entre la vida, la política y la educación: prácticas de libertad y conflictos fecundos", Duoda: estudios de la diferencia sexual, 45, p. 33, recuperado de https:// raco.cat/index.php/DUODA/article/view/271403. Última consulta: 8 de octubre de 2021.

${ }^{36}$ Arendt, H. «Arendt sobre Arendt. Un debate sobre su pensamiento», en H. Arendt, De la historia a la acción, Barcelona, Paidós, 1995, p. 157. 
apertura las que se convierten en clichés ${ }^{37}$, en «cáscaras vacías» ${ }^{38}$. El acontecimiento tiene la potencialidad de cuestionarlas. Y eso, tal vez, exija abandonar algunas ideas, por muy queridas que hayan sido para el llamado pensamiento crítico o la teoría crítica, por mucho que hayan configurado la identidad de la filosofía durante, al menos, los últimos tres siglos al caracterizar la filosofía en términos de crítica, como, por ejemplo, la idea de emancipación y la concepción de la temporalidad en la que se inscribe. Somos nosotras, nosotros, nosotres «quienes -como sostiene Cixoustenemos que encontrar la lengua que profetiza nuestra época ${ }^{39}$.

RECIBIDO: noviembre 2021; ACEPTADO: noviembre 2021

37 V. Arendt, H. «XXXI. Comprensión...», op. cit., p. 372.

38 Arendt, H. "La brecha entre el pasado y el futuro", en H. Arendt, De la historia a la acción, op. cit., p. 87.

39 H. Cixous, «Habitantes del país de la escritura, con Christa Stevens», en M. Segarra (ed.), Entrevistas a Hélène Cixous. No escribimos sin cuerpo, Barcelona, Icaria, 2010, p. 119. 